\title{
Determining Off-cycle Fuel Economy Benefits of 2-Layer HVAC Technology
}

Forrest Jehlik Argonne National Laboratory

Netsanet Chevers Toyota Motor North America R\&D

Matthew Moniot National Renewable Energy Laboratory

Yuanpei Song DENSO International America Inc

Hidekazu Hirabayashi Toyota Motor North America R\&D

Masahiro Nomura DENSO International America Inc

Eric Wood National Renewable Energy Laboratory

Citation: Jehlik, F., Chevers, N., Moniot, M., Song, Y. et al., "Determining Off-cycle Fuel Economy Benefits of 2-Layer HVAC Technology," SAE Technical Paper 2018-01-1368, 2018, doi:10.4271/2018-01-1368.

\section{Abstract}

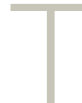

his work presents a methodology to determine the off-cycle fuel economy benefit of a 2-Layer HVAC system which reduces ventilation and heat rejection losses of the heater core versus a vehicle using a standard system. Experimental dynamometer tests using EPA drive cycles over a broad range of ambient temperatures were conducted on a highly instrumented 2016 Lexus RX350 (3.5L, 8 speed automatic). These tests were conducted to measure differences in engine efficiency caused by changes in engine warmup due to the 2-Layer HVAC technology in use versus the technology being disabled (disabled equals fresh air-considered as the standard technology baseline). These experimental datasets were used to develop simplified response surface and lumped capacitance vehicle thermal models predictive of vehicle efficiency as a function of thermal state. These vehicle models were integrated into a database of measured on road testing and coupled with U.S. typical meteorological data to simulate vehicle efficiency across seasonal thermal and operational conditions for hundreds of thousands of drive cycles. Fuel economy benefits utilizing the 2-Layer HVAC technology are presented in addition to goodness of fit statistics of the modeling approach relative to the experimental test data.

\section{Introduction}

\footnotetext{
T
}

he 2012-2025 National fuel economy and greenhouse standards define the regulations for Corporate Average Fuel Economy (CAFE) which must be met by automobile manufacturers. Automobile manufacturer fleet CAFE is determined via a combination of on- and off-cycle methods $s^{[1,2]}$. On-cycle certification is determined from weighted test results over EPA's test cycles. Starting in 2017, manufacturers could supplement on cycle results with offcycle credits. These off cycle credits may be applied for fuel saving technologies whose real-world benefit is not captured by on-cycle testing. There are multiple means to obtain off cycle credits; selection from a pre-defined menu, testing by 5 cycle procedures, or testing via an alternate method. For many technologies the alternate method testing may provide the best estimate of the true fuel savings. For such technologies it is critical to develop robust means to justify the true real-world fuel economy benefits of these off-cycle credits to justify the carbon credit accurately.
A number of studies have demonstrated negative impacts on fuel economy under real-world cold ambient temperatures. Variations in heating ventilation and air conditioning (HVAC) efficiencies, fuel enrichment and spark timing adjustments for catalyst light-off strategies, high rates of heat transfer, and non-linear viscosity of engine lubricants combine to negatively affect powertrain and drive cycle efficiency in cooler ambient conditions $[3,4,5,6,7,8]$. Additionally, regional drive cycle variability plays a large role in overall vehicle efficiency ${ }^{[2]}$. Together, these factors represent important real-world considerations for powertrain design and efficiency.

Previous efforts in understanding real-world effects on vehicle efficiency focused on the vehicle system thermal effects ${ }^{[10]}$. This work presents a methodology to determine the off-cycle fuel economy benefit of a 2-Layer HVAC [11] system versus a vehicle without the technology. Experimental dynamometer tests using EPA drive cycles over a broad range of ambient temperatures were conducted at Argonne National Laboratory (ANL) on an instrumented 2016 Lexus RX350. 
These tests were conducted to measure differences in engine efficiency caused by changes in engine warmup from 2-Layer HVAC technology versus disabled (the latter considered the standard technology baseline). These experimental datasets were used to develop simplified response surface and lumped capacitance vehicle thermal models predictive of vehicle efficiency as a function of thermal state. These vehicle models were integrated into the National Renewable Energy Laboratory's (NREL) Transportation Secure Data Center (TSDC) and coupled with U.S. typical meteorological data to simulate vehicle efficiency across seasonal thermal and operational conditions for tens of thousands of drive cycles. Fuel economy benefits utilizing the 2-Layer HVAC technology versus the vehicle not using the system are presented. Additionally, goodness of fit statistics of the modeling approach relative to the experimental test data are also presented.

\section{2-Layer HVAC Technology Overview}

In colder ambient conditions, cabin thermal losses are mainly caused by heat transfer due to the temperature gradients between the cabin and ambient environment, as well as ventilation losses from outside air being brought into the cabin and the warm air flowing out of cabin. Ventilation heat losses can be reduced by recirculating inside air; however, humidity in the cabin resulting from passenger metabolism, open beverages, snow, and other sources may result in safety hazards due to increased windshield fogging. To reduce ventilation losses and maintain a clear windshield, the test vehicle used 2-layer HVAC consisting of two separate layers and a two-stage fan ${ }^{[11]}$. As shown in Figure 1, the lower part circulates cabin air instead of bringing in fresh air to the foot area while the upper part brings in fresh low humidity air to the windshield. This technology not only increases cabin warm-up speed and reduces window fogging, it also increases the rate at which the engine warms by reducing the cold ambient airflow over the heat exchanger through partially circulating warmer cabin air. Two rotary doors are used in the HVAC inlet to control ambient air brought into cabin as shown in Table 1. In addition to the in cabin comfort and safety benefits, fuel consumption is reduced from the 2-layer HVAC technology by reducing engine warm up time thereby reducing losses related to lubricity and heat transfer.

\section{FIGURE 1 2-Layer air flows}

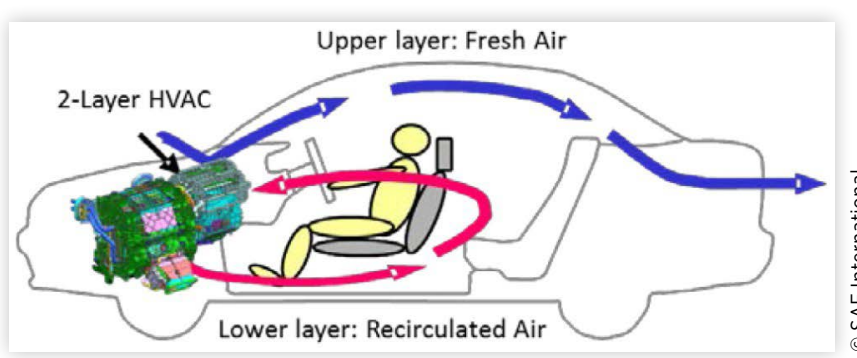

\section{Test Setup}

\section{Facility}

Tests were conducted at ANL's Advanced Powertrain Research Facility (APRF) four-wheel-drive dynamometer test cell [12]. This dynamometer test facility is designed to handle light- to medium-duty sized (maximum $6,350 \mathrm{~kg}$ ) vehicles capable of producing up to $373 \mathrm{~kW}$ of wheel power. The test cell is EPA 5 -cycle capable with ambient temperature capability from $-7^{\circ} \mathrm{C}$ to $+36^{\circ} \mathrm{C}$. Additionally, the test cell can go to colder temperatures (for this work $-18^{\circ} \mathrm{C}$ ). A vehicle fan located at the front of the test cell provides cooling airflow to the vehicle and its powertrain during testing. The simulation fan is a standard vehicle speed-matching fan that fulfills the test regulations for the SC03 air-conditioning (A/C) test. The cell also contains solar lamps simulating a multitude of solar loading conditions experienced in the real-world environment, with a typical target solar loading of $850 \mathrm{~W} / \mathrm{m}^{2}$ at the base of the windshield and/or rear window. The vehicle is restrained to the dynamometer by a tie-down system. Two posts are bolted to T-slot rails on the floor, each post containing a heightadjustable system to restrain the vehicle and to remove vertical load from the wheels on the dynamometer roll.

The test cell contains emission benches capable of bag measuring the criteria emissions total hydrocarbons, oxides of nitrogen, carbon monoxide, soot, as well as carbon dioxide for cycle fuel economy. A data acquisition system is integrated that allows for a multitude of controller area network (CAN), analog, and digital signals to be collected, time aligned, and

TABLE 1 Air intake control in 2-Layer HVAC inlet

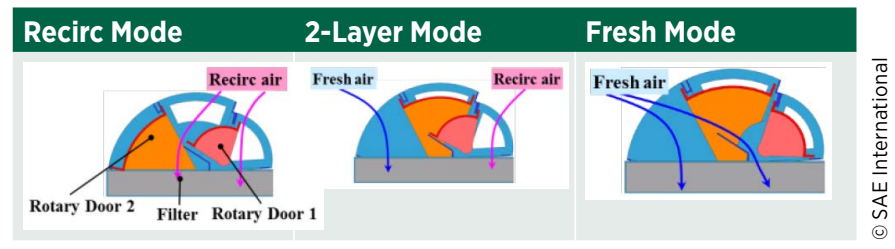

FIGURE 22016 Lexus RX350 test vehicle on APRF dynamometer for testing.

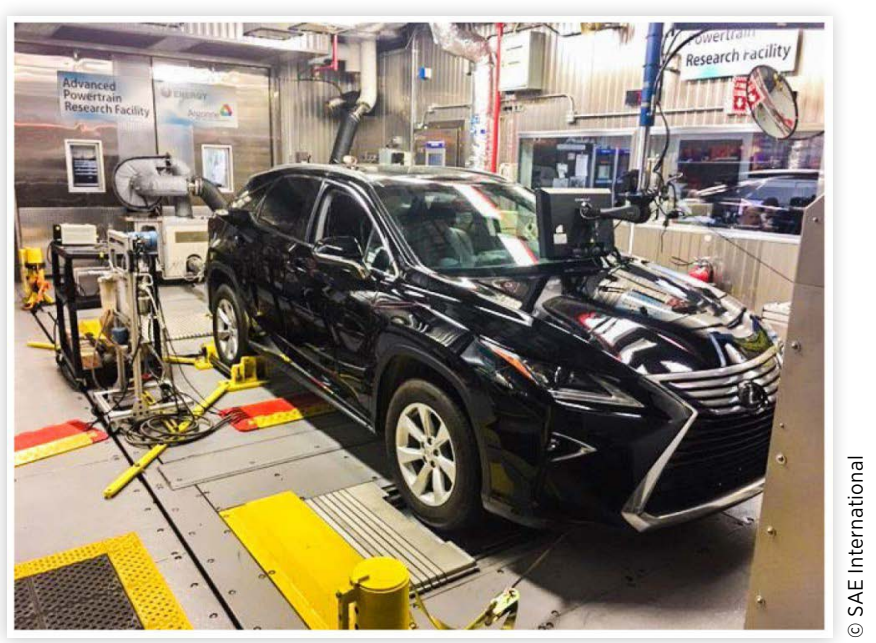


processed directly following a test. Data is collected and time aligned at either 10 or $1 \mathrm{~Hz}$ frequency (channel dependent). The test vehicle and test facility is shown in Figure 2.

\section{Vehicle Instrumentation}

The 2016 Lexus RX350 was extensively instrumented to capture pertinent thermal and energy/power nodes. The engine was instrumented with K-type and T-Type thermocouples to determine coolant, oil, inlet/exhaust temperature at various locations (exhaust port to pre-, mid-bed, and post-catalyst), HVAC system, and interior cabin temperatures. Accuracy for the K-Type thermocouples lies within $5^{\circ} \mathrm{C}$ below $1250^{\circ} \mathrm{C}$ of measurement, decreasing to $1.1^{\circ} \mathrm{C}$ at $100^{\circ} \mathrm{C}$. T-type thermocouples were included in the transmission and vehicle interior, with published $1^{\circ} \mathrm{C}$ accuracy between measurement ranges of -200 to $400^{\circ} \mathrm{C}$. Interior thermocouples were located in the HVAC output vents, occupant head rests, and along a matrix of human reference points in both the passenger and driver side seats to monitor occupant comfort. Strain based torque measurement systems were installed on the half shafts enabling measurement of transmission output torque. For the half shafts, full scale torque measurements were set at $1800 \mathrm{Nm}$ with a maximum static measured repeatability of $0.05 \%$. Fuel flow measurements were collected via three methods: a direct volume displacement fuel meter, an in-line Coriolis fuel meter, as well as the emission bench carbon balance measurements. The direct fuel scale was calibrated within $0.42 \%$ of linear measured error and was used for comparison and model development. Vehicle CAN signals were used to collect engine speed, torque, catalyst light of indicator, transmission gear, torque convertor lockup, vehicle speed, and a host of HVAC settings that were used for the modeling effort. Figure 3 shows the passenger side back seat mannequin

\section{FIGURE 3 Passenger side rear seat mannequin} thermocouple instrumentation.

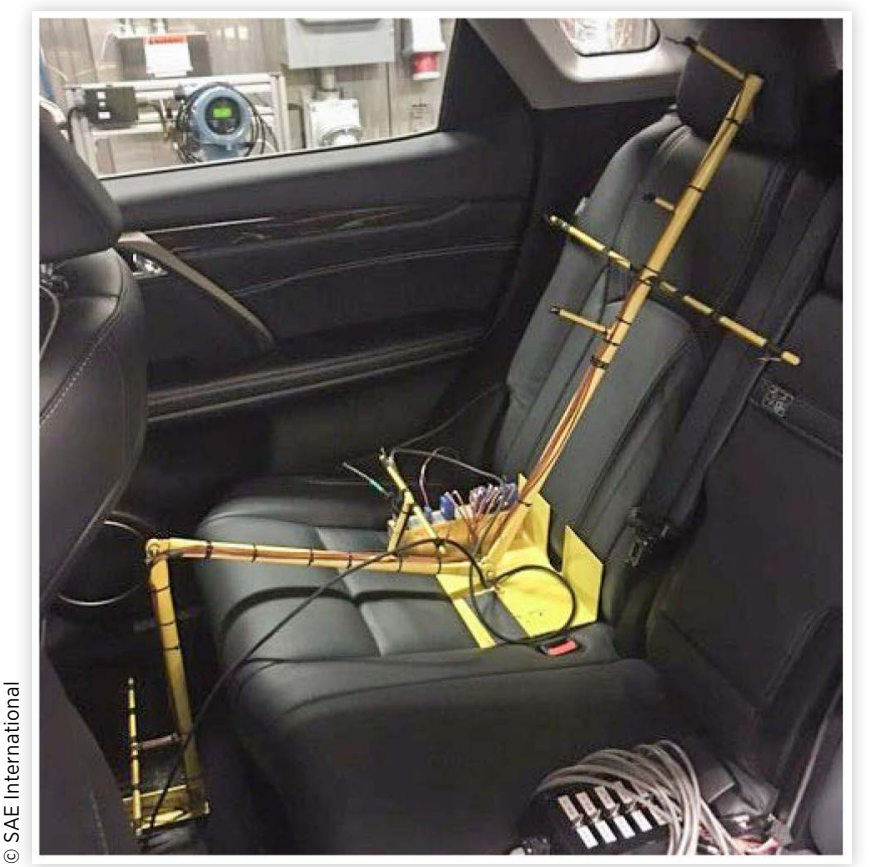

thermocouple system used for the work. Note that the passenger side front seat was similarly instrumented, however, it was difficult getting an image that would show the thermocouple system due to the A-pillar and center console blocking the view so the rear mannequin is shown for reference.

\section{Test Sequence}

To minimize the number of tests while maximizing data fidelity, engine data was compared over the Urban Dynamometer Driving Schedule (UDDS), the Highway Fuel Economy Test (HWFET), and the US06 cycle tests conducted at $+25^{\circ} \mathrm{C}$ (shown in Figure 4). The engine speed/load points for these cycles are shown in Figure 5. By comparing the engine loading over the cycles it was determined that the HWFET cycle speed/load ranges overlapped the other two cycles and therefore tests at the various ambient temperatures using only the UDDS and US06 cycles were necessary for developing the engine efficiency map.

In addition to a wide range of driving behavior, the scope work required a broad sweep of thermal conditions for

\section{FIGURE 4 UDDS, HWFET, and US06 drive cycle profiles.}

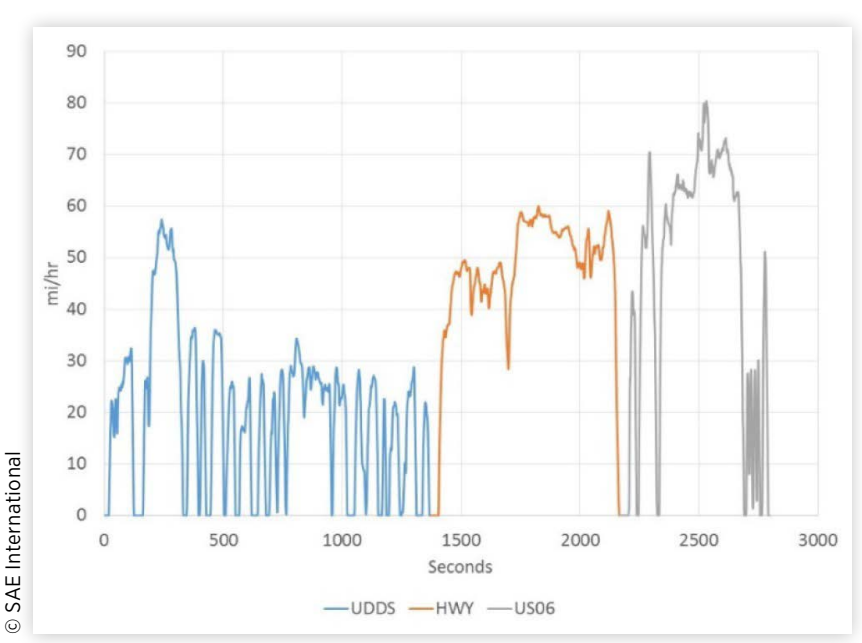

FIGURE 52016 Lexus RX350 velocity and speed/load points over the UDDS, HWFET, and USO6 cycles.

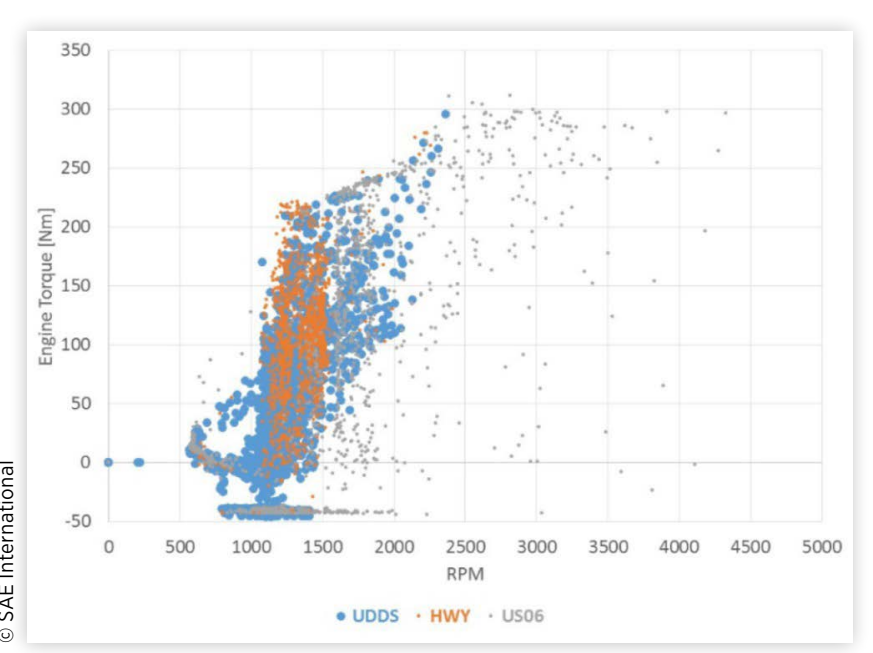


assessment. Both the UDDS and US06 cycles were tested at ambient conditions ranging from $-18^{\circ} \mathrm{C}$ to $+35^{\circ} \mathrm{C}$. Each of these cycles was tested from cold and hot start conditions. Here, a cold start is defined as the vehicle soaking overnight at the test cell temperature. This allowed for cooler powertrain operating data to be collected for both high and low power levels. For hotter ambient tests, the vehicle air conditioner was not used so that the powertrain thermal effects would not be masked by the increased A/C compressor load. For cold tests, the vehicle heater was used and set on $22^{\circ} \mathrm{C}\left(72^{\circ} \mathrm{F}\right)$ Auto. After testing, static vehicle data was collected to determine the rate at which coolant and lubricants cooled following peak operational temperature. Note that additional tests were conducted with the heater in the "on" and "off" positions with no significant measurable load difference recorded.

\section{Drive Cycle Test Results Overview}

Figure 6 and Figure 7 display the engine oil warmup curves of two back-to-back UDDS cycles with a 10 minute soak between the first and second cycle at $-7^{\circ} \mathrm{C}$ and $-18^{\circ} \mathrm{C}$ ambient temperatures. In both cases the cycles were completed with the 2-layer HVAC technology on and off. From these data it is seen that the engine oil temperature rises faster beyond approximately 750 seconds of the first cycle in which there exists sufficient excess engine heat to heat the cabin. Additionally, as the vehicle sits for 10 minutes between the cycles, the higher engine oil temperature in the 2-layer case results in a higher start temperature of the second cycle, and in the case of the $-18^{\circ} \mathrm{C}$ case, remains higher throughout the duration of the test.

Table 2 and Table 3 list the difference in bag fuel consumption $(1 / 100 \mathrm{~km})$ of the two cold ambient test cases with the 2-layer system on and off. Bag numbers are shown in Figure 6 and Figure 7 for reference. Note that in both cold ambient conditions, cycle fuel consumption is improved, on average, $1.75 \%$ for both the $-7^{\circ} \mathrm{C}$ and $-18^{\circ} \mathrm{C}$ ambient cases, and that fuel consumption benefits are seen for both the first and second

FIGURE 6 Engine oil warming profiles, 2-layer on vs disabled baseline, UDDS $\times 2$ at $-7^{\circ} \mathrm{C}$ ambient test cell temperature. 10 min soak time between cycles.

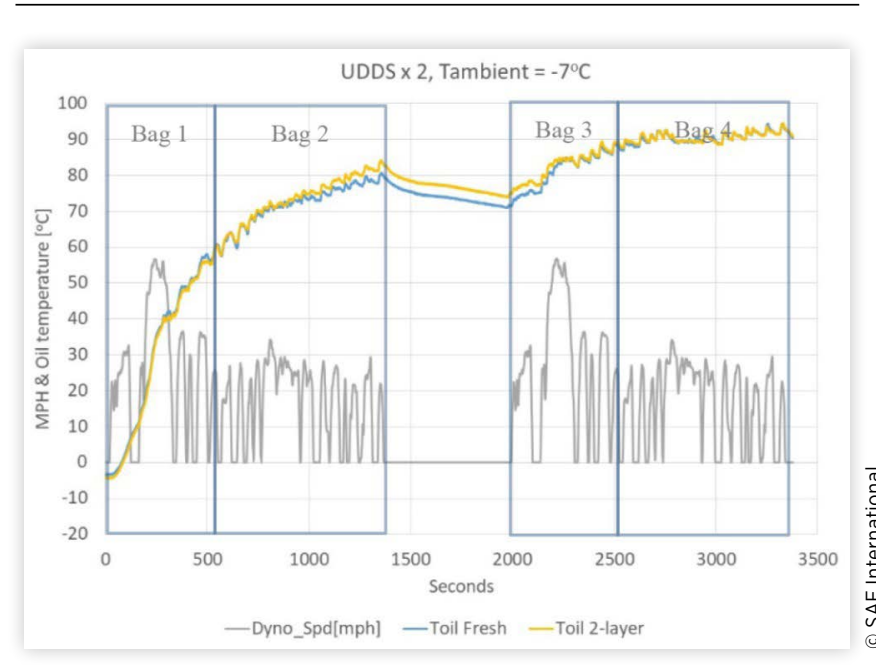

FIGURE 7 Engine oil warming profiles, 2-layer on vs disabled, UDDS $\times 2$ at $-18^{\circ} \mathrm{C}$ ambient test cell temperature. 10 min soak time between cycles.

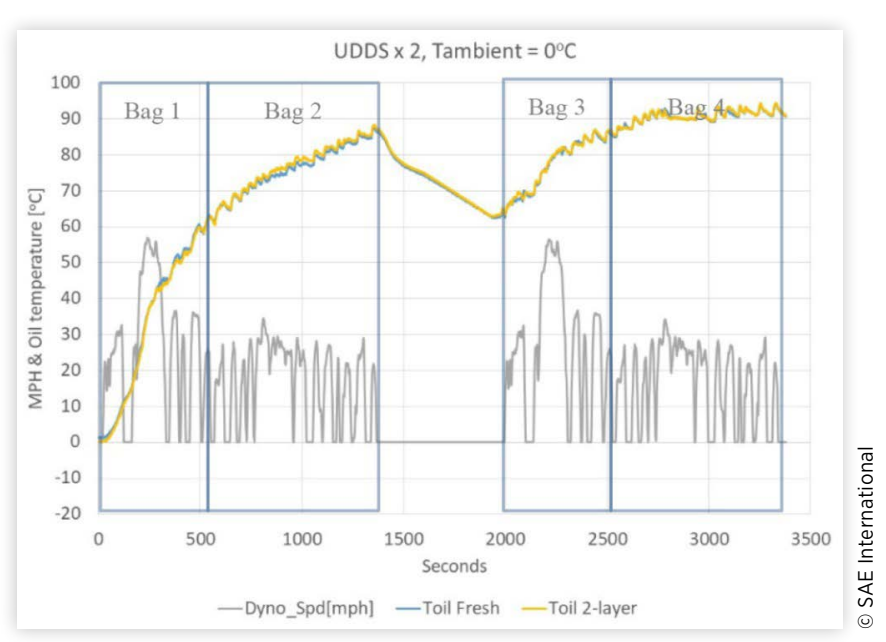

TABLE 24 bag fuel consumption results, UDDS $\times 2,-7^{\circ} \mathrm{C}$ ambient temperature

\begin{tabular}{|c|c|c|c|}
\hline $\begin{array}{l}T_{\text {ambient }} \\
-7^{\circ} \mathrm{C}\end{array}$ & $\begin{array}{l}\text { Disabled baseline } \\
\mathrm{l} / 100 \mathrm{~km}\end{array}$ & $\begin{array}{l}\text { 2-Layer } \\
\text { L/100km }\end{array}$ & $\begin{array}{l}\text { 2-Layer fuel consumption } \\
\text { difference [\%] }\end{array}$ \\
\hline Bag 1 & 13.98 & 13.95 & $-0.2 \%$ \\
\hline Bag 2 & 11.71 & 11.40 & $-2.6 \%$ \\
\hline Cycle 1 & 12.81 & 12.63 & $-1.4 \%$ \\
\hline Bag 3 & 10.00 & 9.59 & $-4.1 \%$ \\
\hline Bag 4 & 10.29 & 10.26 & $-0.2 \%$ \\
\hline Cycle 2 & 10.15 & 9.94 & $-2.1 \%$ \\
\hline
\end{tabular}

TABLE 34 bag fuel consumption results in L/100km, UDDS $\times$ 2, $-18^{\circ} \mathrm{C}$ ambient temperature

\begin{tabular}{|c|c|c|c|}
\hline $\begin{array}{l}T_{\text {ambient }} \\
-18^{\circ} \mathrm{C}\end{array}$ & $\begin{array}{l}\text { Disabled baseline } \\
\text { (L/100km) }\end{array}$ & $\begin{array}{l}\text { 2-Layer } \\
\text { (L/100km) }\end{array}$ & $\begin{array}{l}\text { 2-Layer fuel consumption } \\
\text { difference [\%] }\end{array}$ \\
\hline Bag 1 & 15.67 & 15.56 & $-0.7 \%$ \\
\hline Bag 2 & 12.95 & 12.53 & $-3.3 \%$ \\
\hline Cycle 1 & 14.26 & 13.99 & $-1.9 \%$ \\
\hline Bag 3 & 10.63 & 10.50 & $-1.2 \%$ \\
\hline Bag 4 & 10.75 & 10.53 & $-2.0 \%$ \\
\hline Cycle 2 & 10.69 & 10.52 & $-1.6 \%$ \\
\hline
\end{tabular}

cycle following the 10 minute soak. This suggests the technology may exhibit additional benefits in real-world driving conditions where soak times between cycles occurs in which the powertrain temperature remains above the ambient baseline.

Using the cycle results of the 2-layer vs. the disabled baseline heating system, 5-cycle calculations were completed to understand the benefit from the certified drive cycle testing perspective. In analyzing the inputs to the 5-cycle results it was determined that the benefit would be realized only in the city portion of the calculation for the $-7^{\circ} \mathrm{C}$ bag 2 portion of testing. This may be seen in the following calculations in which the running fuel consumption (Running FC) contains an $18 \%$ proportional equivalent weighting of the $-7^{\circ} \mathrm{C}\left(+20^{\circ} \mathrm{F}\right)$ bag 2 fuel consumption $\left(\mathrm{Bag}_{20}\right)$ and $-7^{\circ} \mathrm{C}\left(+20^{\circ} \mathrm{F}\right)$ bag 3 fuel consumption $\left(\mathrm{Bag}_{20}\right)$. The correlations are here shown: 
City FE $=0.905 \times \frac{1}{\text { Start FC }+ \text { Running FC }}$, where

Start FC( gallons per mile)

$$
=0.33 \times\left(\frac{\left(0.76 \times \text { StartFuel }_{75}\right)+\left(0.24 \times \text { StartFuel }_{20}\right)}{4.1}\right),
$$

Where

Running $F C=$

$$
\begin{aligned}
& 0.82 \times\left[\frac{0.48}{B a g 2_{75} F E}+\frac{0.41}{B a g 3_{75} F E}+\frac{0.11}{\text { US06City FE }}\right] \\
& +0.18 \times\left[\frac{0.5}{B a g 2_{20} F E}+\frac{0.5}{B a g 3_{20} F E}\right]
\end{aligned}
$$$$
+0.133 \times 1.083 \times[A / C F C]
$$$$
A / C F C=\left[\frac{1}{S C 03 F E}-\left(\frac{0.61}{B a g 3_{75} F E}+\frac{0.39}{B a g 2_{75} F E}\right)\right]
$$

From this the 5-cycle fuel consumption comparison between the 2-layer and disabled system were calculated and shown in Table 4 . Results show a $0.32 \%$ reduction in 5-cycle fuel consumption using the 2-layer technology compared to the disabled benchmark.

To further demonstrate and quantify the effects of engine thermal state on efficiency and the impacts that the 2-layer technology may have, data from engine speed, load, fueling rate, and lubricant temperature were used to develop an engine efficiency

\begin{tabular}{|c|c|c|c|}
\hline & $\begin{array}{l}\text { Disabled } \\
\text { baseline }\end{array}$ & 2-Layer & $\begin{array}{l}\text { Difference } \\
\text { [\%] }\end{array}$ \\
\hline Hwy Fuel Econ. [l/100km] & 9.97 & 9.97 & - \\
\hline City Fuel Econ. [l/100km] & 12.39 & 12.35 & $0.32 \%$ \\
\hline
\end{tabular}

TABLE 45 cycle fuel consumption comparison, RX350, 2-Layer vs. disabled HVAC system

FIGURE 8 Engine efficiency as a function of power output and oil temperature, response surface model derived from transient test cycle data.

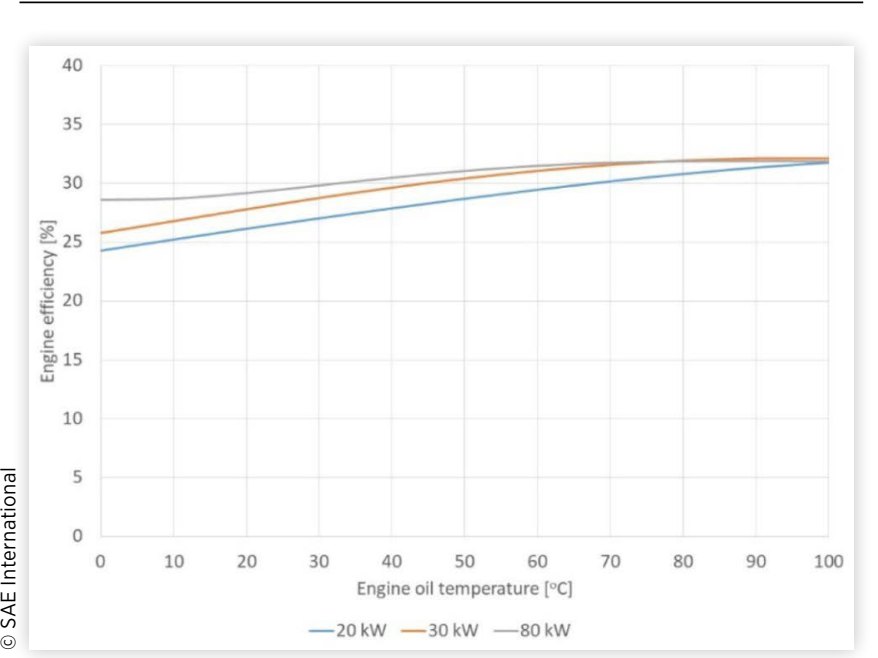

FIGURE 9 Kinematic viscosity of engine oil as a function of temperature. Note logarithmic viscosity scale. Data taken from EES (engine-oil unused) [16].

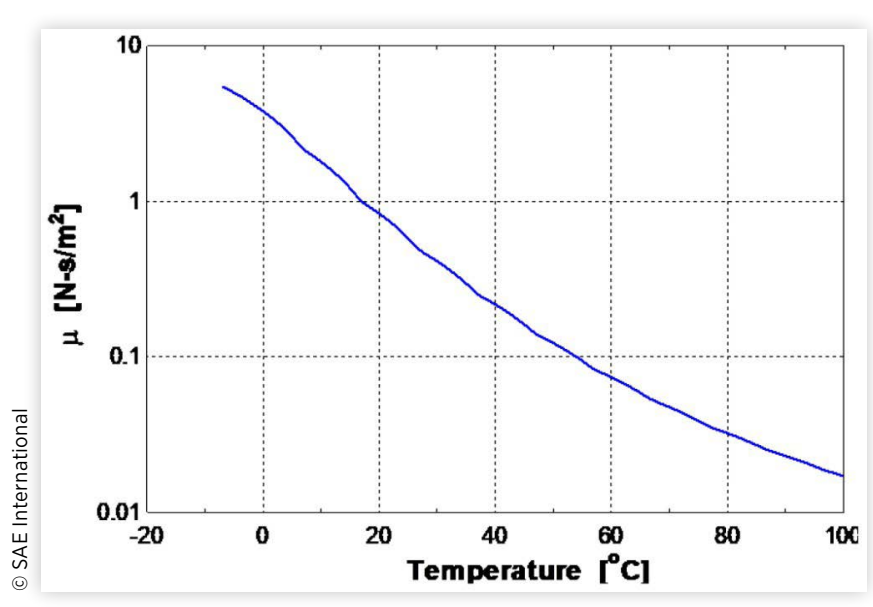

correlation. The ratio of engine output power was taken relative to the fueling rate, and the model used to show how this efficiency changes over the engine thermal state (represented by oil temperature). Results are shown in Figure 8. For the 20, 30, and $80 \mathrm{~kW}$ power levels shown, engine efficiency increases as engine oil temperature increases while efficiency appears to assemptote near oil temperatures of approximately $\sim 100^{\circ} \mathrm{C}$. Note that for the UDDS cycle, the average power level seen is approximately $30 \mathrm{~kW}$ so that the power levels shown for demonstration are pertinent to the cycle results shown. These modeling results suggest that greater benefits may be had from the 2-layer system at lower oil temperatures, yet that diminishing benefits may still be realized near oil equilibria operating temperature as well.

These results may be further understood by noting the temperature effect on lubricant oil viscosity. Plotting the kinematic viscosity ${ }^{[16]}$ of unused engine oil versus temperature shown in Figure 9 , the strong non-linearity of viscosity relative to temperature indicates the excessive friction forces at lower temperatures for the engine. Similar results would be observed for transmission and gear oil as well, though, may be more or less in magnitude.

\section{Thermal Component Model Development}

While many modeling approaches exist to estimate vehicle efficiency relative to road loads and powertrain component efficiency, less effort has been expended characterizing the efficiency of internal combustion engines with respect to thermal state. The focus of this work centers on the development of a simplified methodology that characterizes thermal effects in real-world driving conditions without using overly complex models dependent upon comprehensive component data. Not only are such data not generally available, but simulations using unnecessarily complex models provide diminishing returns in terms of accuracy and create computational burdens when applied to large databases of real-world drive cycles.

The following simplified component models provide a means for predicting component warm-up times and 
FIGURE 10 Lumped capacitance thermal modeling structure

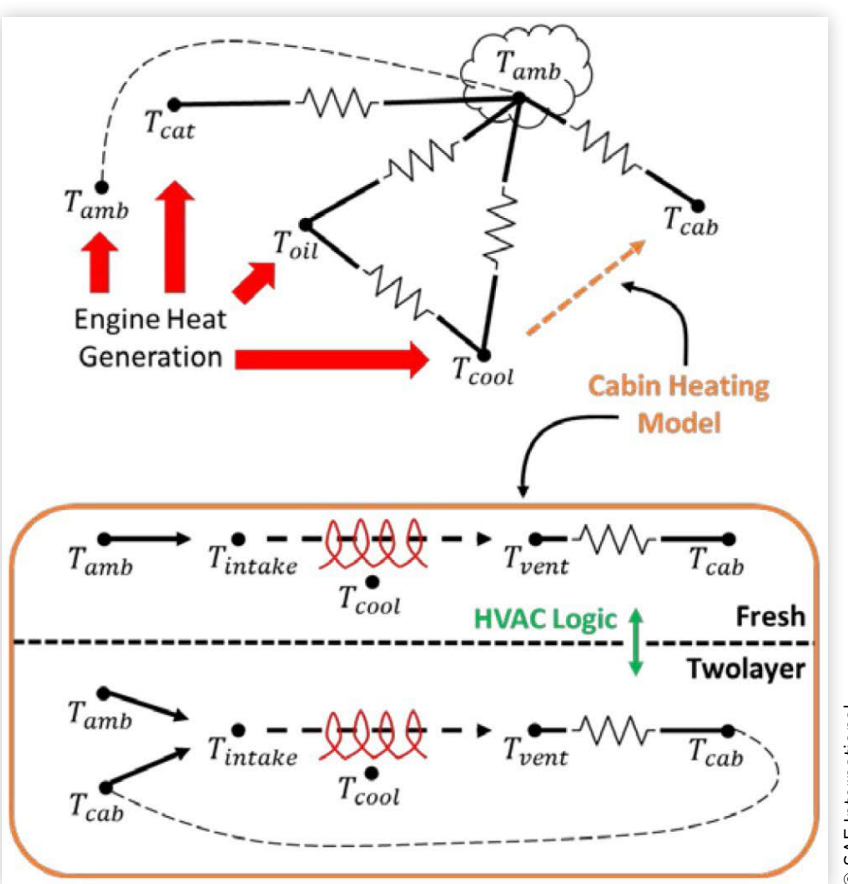

steady-state operating points sensitive to ambient conditions. The generalized approach involves response surface methodology models coupled with simplified lumped capacitance parameter-based models. Application of the Nelder-Mead nonlinear optimization method solves for the unknown coefficients to minimize model error relative to vehicle measured results of fuel consumption over the drive cycles and thermal conditions tested. In total, thermal component models were created for the engine oil, engine coolant, exhaust catalyst, and cabin. Additionally, an engine fueling model was incorporated which delivers heat to three nodes as a function of the instantaneous engine waste heat generation. Figure 10 describes the relationships between the individual component models including the cabin heating structure for both the disabled baseline and 2-Layer settings.

\section{Engine Efficiency}

A simplified model of the engine fueling rate was developed as a function of engine output power, engine oil temperature, and the exhaust catalyst temperature. The engine fueling rate is described by a response surface model with engine output power and engine oil temperature as model inputs ${ }^{[5]}$. The catalyst model is a simplified exponential decay equation that takes into consideration the catalyst temperature until lightoff. This equation adds a decaying amount of fuel until a certain catalyst temperature is reached. The engine fueling equations are shown for reference:

$$
\begin{gathered}
\text { fuel }=f_{1}\left(P_{\text {out }}, T_{\text {oil }}\right)+f_{2}\left(T_{\text {cat }}\right) \\
f_{1}\left(P_{\text {out }}, T_{\text {oil }}\right)=\left(c_{1}+a_{1,0} P_{\text {out }}+a_{0,1} T_{\text {cat }}+a_{1,1} P_{\text {out }} T_{\text {cat }}+a_{2,0} P_{\text {out }}{ }^{2}\right. \\
\left.+a_{0,2} T_{\text {cat }}{ }^{2}+a_{2,1} P_{\text {out }}{ }^{2} T_{\text {cat }}+a_{1,2} P_{\text {out }} T_{\text {cat }}{ }^{2}+a_{3} P_{\text {out }}{ }^{3}\right)^{2}+c_{2}
\end{gathered}
$$

$$
f_{2}\left(T_{c a t}\right)=\max \left(0, \frac{a_{1}}{T_{c a t}{ }^{2}+a_{2} T_{c a t}+a_{3}}\right), \text { while } T_{c a t}<400
$$

Following the Nelder-Mead solution of the coefficients, plots of the engine efficiency as a function of the engine oil temperature and power output were generated, as well as the time-based comparison between the model's predicted fuel flow and the actual measured data.

Figure 11 illustrates the significant impact engine lubricant temperature has on efficiency. An island of optimal efficiency (approximately 33\%) exists at power levels between 70 $\mathrm{kW}$ and $100 \mathrm{~kW}$ and oil temperatures of $+75^{\circ} \mathrm{C}$ to $+100^{\circ} \mathrm{C}$. Yet at identical power levels, as engine oil temperature decreases to $-17^{\circ} \mathrm{C}$, engine efficiencies fall to between $24 \%-26 \%$, an approximate $33 \%$ decrease in overall efficiency for identical power outputs. This underscores the effect decreased engine oil temperature plays on engine efficiency.

As an example of the time-based comparison of the modeled fueling rate compared to experimental data, Figure 12 shows results for a 200-second segment of a US06 cycle

FIGURE 11 Optimized engine efficiency map as function of output mechanical power and engine oil temperature using data from both cold start and warm conditions.

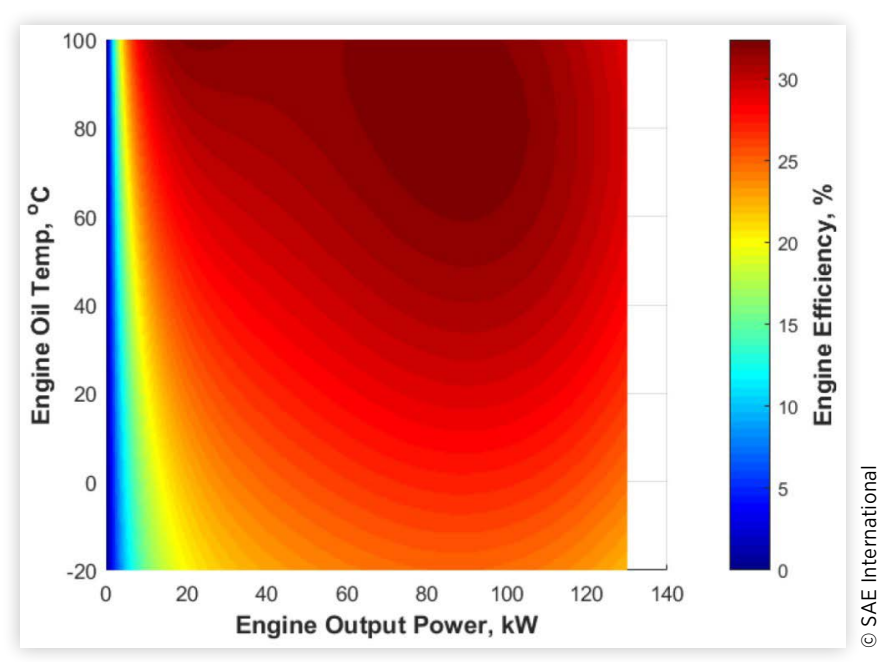

FIGURE 12 Example time series data of engine fueling rate (200-second section of US06S). Measured test data from chassis dynamometer (solid black) overlaid with model estimate (solid red).

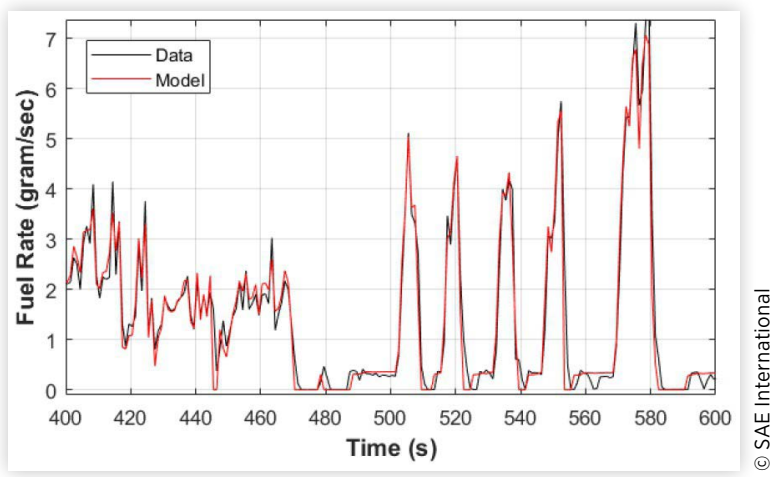


TABLE 5 Cumulative fuel error between measured test data and model estimate (positive error indicates model overestimation).

\begin{tabular}{|c|c|c|c|c|}
\hline \multirow[b]{2}{*}{ Test Cell Temp } & \multicolumn{2}{|c|}{ Disabled baseline } & \multicolumn{2}{|c|}{ 2-Layer } \\
\hline & UDDS & USO6 & UDDS & USO6 \\
\hline$-18^{\circ} \mathrm{C}$ & $-3.5 \%$ & $-1.7 \%$ & $-0.7 \%$ & $-2.2 \%$ \\
\hline$-7^{\circ} \mathrm{C}$ & $-1.3 \%$ & $-1.9 \%$ & $1.3 \%$ & $-1.7 \%$ \\
\hline
\end{tabular}

conducted at $-18^{\circ} \mathrm{C}$. As these results show, the model matches extremely well with the actual fuel flow measurements recorded during testing.

Finally, calculations were performed to determine the relative accuracy of the simplified models to predict overall drive cycle fuel consumption for the various drive cycles and temperatures used to develop the model. Table 5 contains results for cumulative fuel error between the engine model and the test data for cycles with cold starts in cold cell temperatures. Results from these tests are emphasized because vehicle warmup conditions are when the 2-Layer system is active and when any fuel consumption savings can be realized. The results listed show that the maximum predicted deviation from the measured results is $-3.51 \%$. The root mean square cycle error from the measured results of the cycles in question is $1.95 \%$.

\section{Engine Oil Temperature}

A simplified lumped capacitance model of engine oil temperature was developed from experimental data. The model includes convective heat transfer from the oil to environment, convective transfer between the oil and coolant, and the difference between the power in (fuel mass flow rate) and engine power out. The convective heat transfer term for the engine oil includes a vehicle velocity based function to reflect forced convection as vehicle speed increases. This methodology simplifies the process while resulting in accurate estimations. The equations are shown below and in Figure 13.

$$
\dot{T}_{\text {oil }}=\frac{h_{1}\left(T_{\text {amb }}-T_{\text {oil }}\right)+h_{2}\left(T_{\text {cool }}-T_{\text {oil }}\right)+\alpha\left(P_{\text {out }}-P_{\text {in }}\right)}{m_{\text {oil }}}
$$

\section{FIGURE 13 Example time series data of engine oil} temperature (measured at dipstick). Measured test data from chassis dynamometer (solid black) overlaid with model estimate (solid red) for a back to back UDDS cycle in a $-18^{\circ} \mathrm{C}$ cell and a cold start initial vehicle condition.

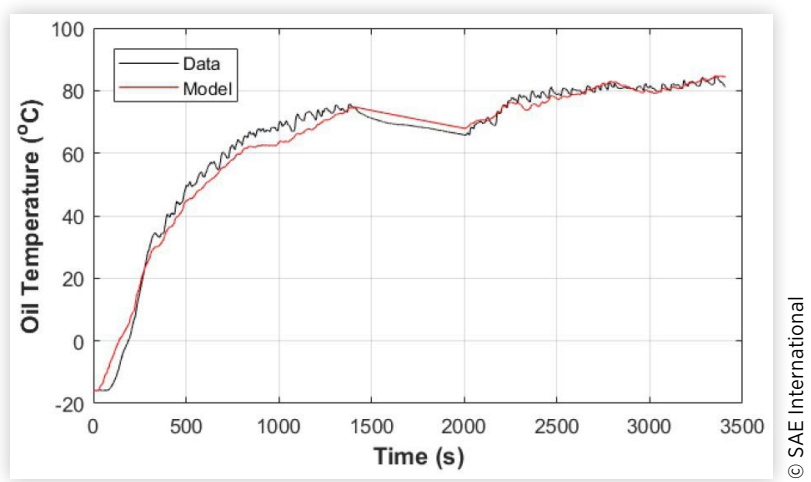

TABLE 6 Root mean square of instantaneous error between measured and model-estimated engine oil temperature. The nominal operating temperature of the engine oil is approximately $+95^{\circ} \mathrm{C}$.

\begin{tabular}{|c|c|c|c|c|}
\hline \multirow[b]{2}{*}{ Test Cell Temp } & \multicolumn{2}{|c|}{ Disabled baseline } & \multicolumn{2}{|c|}{ 2-Layer } \\
\hline & UDDS & US06 & UDDS & US06 \\
\hline$-18^{\circ} \mathrm{C}$ & $3.1^{\circ} \mathrm{C}$ & $3.4^{\circ} \mathrm{C}$ & $4.1^{\circ} \mathrm{C}$ & $3.8^{\circ} \mathrm{C}$ \\
\hline$-7^{\circ} \mathrm{C}$ & $4.3^{\circ} \mathrm{C}$ & $3.0^{\circ} \mathrm{C}$ & $4.1^{\circ} \mathrm{C}$ & $2.7^{\circ} \mathrm{C}$ \\
\hline
\end{tabular}

$$
h_{1}=a_{1} v_{v e h}+a_{2}
$$

Where:

$a_{x}=$ lumped coefficients to solve for,

$h_{x}=$ lumped convective heat transfer coefficients,

$m_{\text {oil }}=$ mass of engine oil,

$P_{i n}=$ engine input power (fuel rate lower heating value),

$P_{\text {out }}=$ engine output power (brake power),

$T_{a m b}=$ ambient temperature,

$T_{\text {cool }}=$ coolant temperature,

$T_{\text {oil }}=$ oil temperature,

$v_{v e h}=$ vehicle velocity.

Additionally, root mean square error analysis of the instantaneous model-predicted engine oil and actual measured temperature was completed. The results of this analysis listed in Table 6 show that the average of the instantaneous root mean square error deviation from the actual temperature is $3.6^{\circ} \mathrm{C}$. (For reference, the nominal engine oil operating temperature is approximately $+95^{\circ} \mathrm{C}$ ).

\section{Engine Coolant Temperature}

Similar to the engine oil model, a simplified lumped capacitance model of engine coolant temperature was developed. This model includes convective heat transfer from the coolant to environment, between the coolant and oil, fractional engine power loss, and heat transfer between the coolant and the intake air to be heated for passenger comfort. A logical operator is included that accounts for the thermostat opening which increases heat transfer from the coolant to the ambient environment and accounts for vehicle velocity and forced convective heat transfer. An additional logical operator controls the temperature of the intake air forced through the heater core which is dependent upon the current HVAC setting. Note that the intake temperature is higher while the 2-Layer system is active, reflecting a reduction in the thermal load from the engine coolant. The equations and relative predicted model accuracy are shown below and in 3 (see Equations 5 and $\underline{6}$ for additional variable definitions).

$\dot{T}_{\text {cool }}=\frac{h_{1}\left(T_{\text {amb }}-T_{\text {cool }}\right)+h_{2}\left(T_{\text {oil }}-T_{\text {cool }}\right)+h_{3} f_{s}\left(T_{\text {intake }}-T_{\text {cool }}\right)+\alpha\left(P_{\text {out }}-P_{\text {in }}\right)}{m_{\text {cool }}}$

$$
\begin{aligned}
& \text { if } T_{\text {cool }}<T_{\text {set }}: h_{1}=a_{1} v_{v e h}+a_{2}, \text { else }: h_{1}=a_{3} v_{v e h}+a_{4} \\
& \text { if HVAC }=\text { Fresh }: T_{\text {intake }}=T_{a m b}, \\
& \text { if } H V A C=\text { Twolayer }: T_{\text {intake }}=(1-c) T_{a m b}+c T_{c a b}
\end{aligned}
$$$$
f_{s}=f\left(T_{a m b}, T_{c o o l}, T_{c a b}\right)
$$ 
TABLE 7 Root mean square of instantaneous error between measured and model-estimated engine coolant. The nominal operating temperature of the engine coolant is approximately $+90^{\circ} \mathrm{C}$.

\begin{tabular}{|c|c|c|c|c|}
\hline & \multicolumn{2}{|c|}{ Disabled baseline } & \multicolumn{2}{|c|}{ 2-Layer } \\
\hline Test Cell Temp & UDDS & US06 & UDDS & US06 \\
\hline$-18^{\circ} \mathrm{C}$ & $7.4^{\circ} \mathrm{C}$ & $9.4^{\circ} \mathrm{C}$ & $5.4^{\circ} \mathrm{C}$ & $9.8^{\circ} \mathrm{C}$ \\
\hline$-7^{\circ} \mathrm{C}$ & $6.4^{\circ} \mathrm{C}$ & $8.7^{\circ} \mathrm{C}$ & $6.8^{\circ} \mathrm{C}$ & $7.4^{\circ} \mathrm{C}$ \\
\hline
\end{tabular}

Where:

$T_{\text {intake }}=$ intake air to the coolant coil,

$m_{\text {cool }}=$ coolant mass,

$T_{c a b}=$ cabin temperature,

$c=$ recirculation fraction during 2 -Layer operation,

$H V A C=$ binary operator describing vehicle HVAC setting

$f_{s}=$ relative cabin blower fan speed.

Similar to the oil model, a root mean square error analysis of the instantaneous coolant model and actual measured temperature was completed. The results of this analysis listed in Table 7 show that the average of the instantaneous root mean square deviation from the actual coolant temperature is $7.6^{\circ} \mathrm{C}$. (For reference, the nominal engine coolant operating temperature is approximately $+90^{\circ} \mathrm{C}$ ). As was the case for engine oil temperature, these deviations do not last the entirety of the simulation, but rather for short durations of the simulated cycle.

\section{Exhaust Catalyst Temperature}

A catalyst thermal model was also created to account for fueling rate enrichment prior to catalyst light off. A simplified lumped capacitance method was applied that included a convective term accounting for heat transfer away from the catalyst to the ambient environment, as well as a fraction of the difference in power between the energy into and out of the engine. As was the case with the coolant and oil, a vehicle velocity term is added to account for forced convection. The equations are listed below, as well as an example of the simultaneous modeled catalyst temperature versus measured results shown in Figure 15 (see $\underline{\text { Equations } 5}$ and $\underline{6}$ for variable definitions).

FIGURE 14 Example time series data of engine coolant temperature (measured at heater core inlet). Measured test data from chassis dynamometer (solid black) overlaid with model estimate (solid red) for a back to back UDDS cycle in a $-18^{\circ} \mathrm{C}$ cell and a cold start initial vehicle condition.

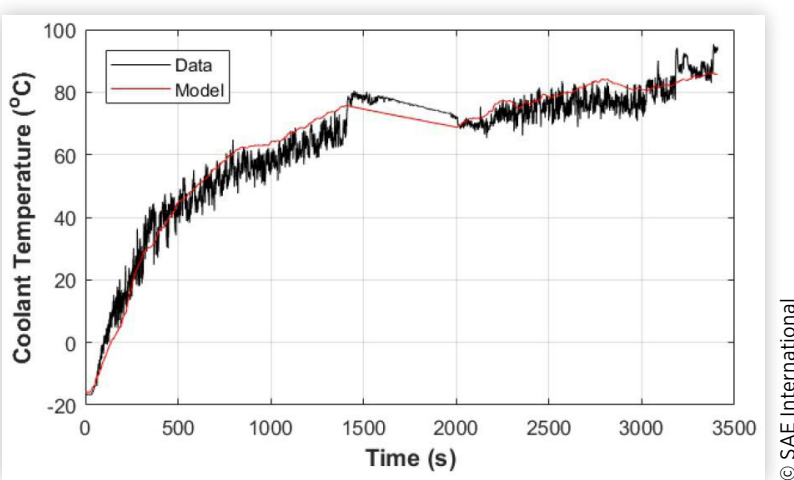

$$
\begin{gathered}
\dot{T}_{c a t}=\frac{h\left(T_{a m b}-T_{c a t}\right)+\alpha\left(P_{\text {out }}-P_{\text {in }}\right)}{m_{\text {cat }}} \\
h=a_{h 1} v_{v e h}+a_{h 2} \\
\alpha=a_{\alpha 1} T_{c a t}+a_{\alpha 2}
\end{gathered}
$$

As in the case for oil and coolant models, instantaneous root mean square error analysis was conducted to determine the relative accuracy of the modeled catalyst temperature against measured results. Table 8 shows the average of the instantaneous root mean square error between the modelpredicted and actual temperature is $57.4^{\circ} \mathrm{C}$. (For reference, the nominal exhaust catalyst operating temperature is approximately $+450^{\circ} \mathrm{C}$ ). Note that catalyst temperature accuracy is most important below $+400^{\circ} \mathrm{C}$, as enrichment effects are not considered above this threshold. As such, any overshooting above the enrichment cutoff is not consequential to fuel model accuracy.

\section{Cabin Temperature}

Finally, a thermal model was created which describes the cabin temperature versus time to account for the impact of HVAC setting on vehicle fuel consumption. Lumped capacitance relationships are included which relate the cabin air temperature to the ambient air and the register outlet air. Similar to the previous thermal models, a vehicle velocity term is included to account for forced convection. Additionally, the relationship between the vent outlet temperature and the cabin temperature is a function of the fan blower speed. The

\section{FIGURE 15 Example time series data of exhaust catalyst} temperature (measured pre-catalyst). Measured test data from chassis dynamometer (solid black) overlaid with model estimate (solid red) for a back to back UDDS cycle in a $-7^{\circ} \mathrm{C}$ cell and a cold start initial vehicle condition.

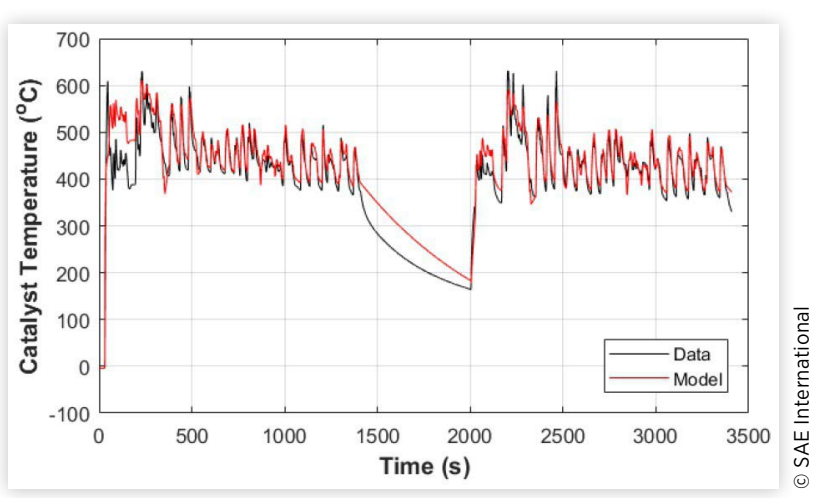

TABLE 8 Root mean square of instantaneous error between measured and model-estimated exhaust catalyst temperature.

\begin{tabular}{|c|c|c|c|c|}
\hline & \multicolumn{2}{|c|}{ Disabled baseline } & \multicolumn{2}{|c|}{ 2-Layer } \\
\hline Test Cell Temp & UDDS & US06 & UDDS & US06 \\
\hline$-18^{\circ} \mathrm{C}$ & $45.2^{\circ}$ & $69.3^{\circ} \mathrm{C}$ & $44.6^{\circ} \mathrm{C}$ & $81.6^{\circ} \mathrm{C}$ \\
\hline$-7^{\circ} \mathrm{C}$ & $35.0^{\circ} \mathrm{C}$ & $74.6^{\circ} \mathrm{C}$ & $35.5^{\circ} \mathrm{C}$ & $73.5^{\circ} \mathrm{C}$ \\
\hline
\end{tabular}
The nominal operating temperature of the exhaust catalyst is approximately $+450^{\circ} \mathrm{C}$. 
FIGURE 16 Example time series data of cabin temperature (measured from the car sensor). Measured test data from chassis dynamometer CAN signal (solid black) overlaid with model estimate (solid red) for $2 x$ UDDS cycle in a $-18^{\circ} \mathrm{C}$ cell and a cold start initial vehicle condition. An additional thermocouple channel is shown for reference.

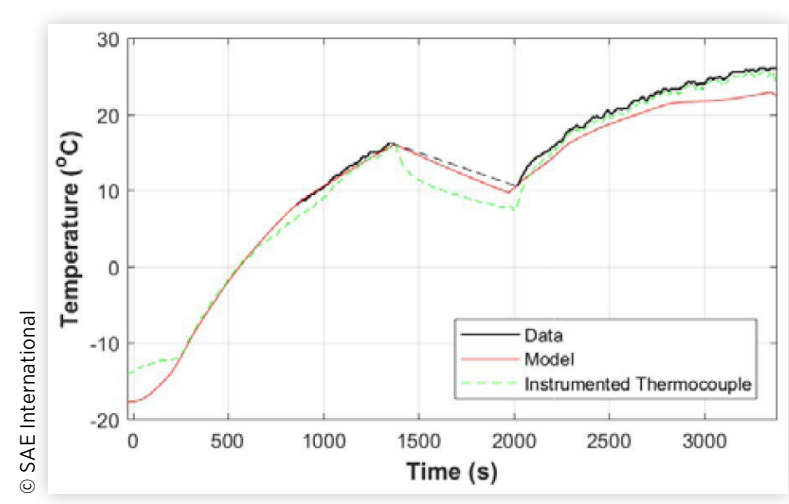

TABLE 9 Root mean square of instantaneous error between measured and model-estimated vehicle cabin temperature after first 10 minutes. The nominal cabin temperature is approximately $+28^{\circ} \mathrm{C}$ upon vehicle warmup.

\begin{tabular}{|c|c|c|c|c|}
\hline \multirow[b]{2}{*}{ Test Cell Temp } & \multicolumn{2}{|c|}{ Disabled baseline } & \multicolumn{2}{|c|}{ 2-Layer } \\
\hline & UDDS & US06 & UDDS & USO6 \\
\hline$-18^{\circ} \mathrm{C}$ & $2.3^{\circ} \mathrm{C}$ & $1.2^{\circ} \mathrm{C}$ & $3.4^{\circ} \mathrm{C}$ & $2.5^{\circ} \mathrm{C}$ \\
\hline$-7^{\circ} \mathrm{C}$ & $1.6^{\circ} \mathrm{C}$ & $3.3^{\circ} \mathrm{C}$ & $1.8^{\circ} \mathrm{C}$ & $1.2^{\circ} \mathrm{C}$ \\
\hline
\end{tabular}

equations are listed below, as well as an example of the simultaneous modeled cabin temperature versus measured results.

$$
\begin{gathered}
\dot{T}_{c a b}=\frac{h_{1}\left(T_{a m b}-T_{c a b}\right)+h_{2} f_{s}\left(T_{\text {vent }}-T_{c a b}\right)}{m_{c a b}} \\
h_{1}=a_{h 1} v_{v e h}+a_{h 2} \\
T_{\text {vent }}=T_{\text {intake }}+h_{3} f_{s}\left(T_{\text {cool }}-T_{\text {intake }}\right)
\end{gathered}
$$

Figure 16 shows a comparison between the modeled cabin temperatures versus the measured cabin temperature. The CAN signal calibrated against has a lower limit on reported values; a nearby thermocouple reporting cabin temperature is also included as a reference. A root mean square error analysis was performed for the cabin model as well. Table 9 contains instantaneous error values corresponding to values after 10 minutes of testing for cycles involving cold start and cold ambient conditions. The average root mean square error for the cabin model for the cycles in question is $2.2^{\circ} \mathrm{C}$.

\section{Model Calibration}

A final step of calibrating the model at an aggregate level to the test data was performed to ensure the model accurately captured the impact of the 2-layer technology on vehicle fuel economy. While accuracy within the temperature profiles is important, the primary concern of the investigation was to understand the real-world fuel consumption benefit of the
FIGURE 17 Cycle level technology benefit across two repeated cycles and two cell temperatures. A static value was calibrated across cases to improve agreement between the model and test data.

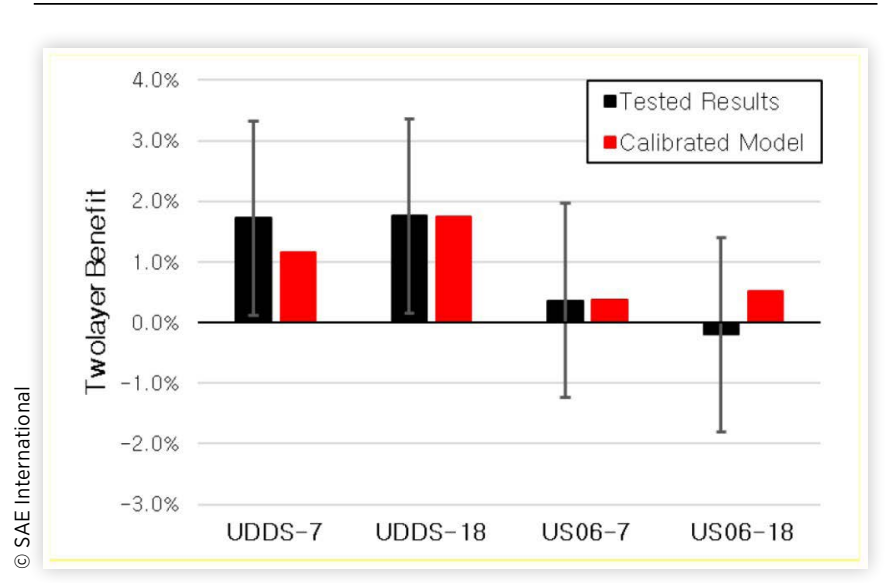

technology. Figure 17 shows the cycle level benefit for the tested results and the modeled results after calibration, which included adjusting the available engine waste heat experienced by component models to better agree with tested warmup profiles. In the four cases shown the drive schedule impacts the technology benefit significantly more than just the cell temperature. Thus, incorporating real-world velocity profiles in the analysis was considered to be extremely important. Note that only two repeat tests were available at a single combination of ambient temperature and drive cycle to define error bars.

\section{Real-World Simulations}

Calculation of vehicle road loads in this analysis was performed using NREL's Future Automotive Systems Technology Simulator (FASTSim) ${ }^{[18]}$. FASTSim is a vehicle simulation tool used to evaluate the impact of various technologies on vehicle performance, cost, and utility in conventional and advanced technology powertrains. FASTSim calculates the power necessary to meet a given speed trace and overcome road loads (rolling, aerodynamic, kinetic, and potential) while considering component limitations, system losses, and auxiliary loads. Given the required engine output power at each time step the engine fuel use is calculated via the thermally sensitive efficiency map as previously detailed, while the differential equations describing the thermal response of engine oil, engine coolant, exhaust catalyst, and cabin are evaluated.

To evaluate real-world effects such as drive cycle intensity, dwell time distributions, and ambient conditions, the simplified model was simulated over a large set of real-world drive cycles using an array of ambient temperatures. Over one million miles of real-world drive cycle data was sourced from the National Renewable Energy Laboratory's Transportation Secure Data Center ${ }^{[18]}$ from dozens of U.S. cities and used to evaluate the RX350 model with and without the 2-Layer HVAC system. Figure 18 shows a geographic distribution of TSDC real-world drive cycle data. 
FIGURE 18 Geographic coverage of $1 \mathrm{~Hz}$ drive cycle data currently available in the Transportation Secure Data Center (TSDC).

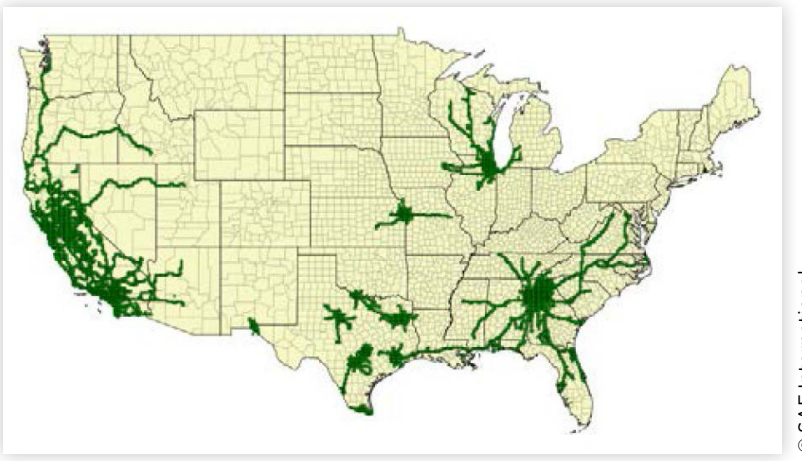

Figure 19 presents real-world trip start time data from the TSDC. A composite of approximately 146,000 trips (consisting of second-by-second speed data) collected across the United States reveals a distribution of trip start times that coincides with traditional traffic patterns (low volumes overnight, a sharp spike in the morning rush hour, a smaller spike around the noon lunch hour, highest volumes around afternoon rush hour, and a slow decline into the evening).

Figure 20 takes the same 146,000 TSDC trips and creates a distribution with respect to soak time (vehicle time in key-off state between trips). Approximately one-third of trips are observed to start following a soak time of greater than four hours; these are trips that can confidently be classified as cold starts. The remaining two-thirds of trips can be thought of as pseudo cold starts given that most engine compartments can be expected to retain some appreciable amount of heat during a park event of this duration. Notably, $20 \%$ of trips are observed to start following a soak time of less than 15 minutes.

These real-world drive cycle data are simulated over a range of ambient temperatures and weighted according to EPA estimates of vehicle miles travelled (VMT) by ambient temperature as shown in Figure $21{ }^{[19]}$. This distribution results in a VMT-weighted average ambient temperature of $+14.4^{\circ} \mathrm{C}$. As the 2-layer system in question is modeled as providing fuel economy benefits only during operation of the cabin heating

\section{FIGURE 19 TSDC Trip start-time distribution (by hour} of day).

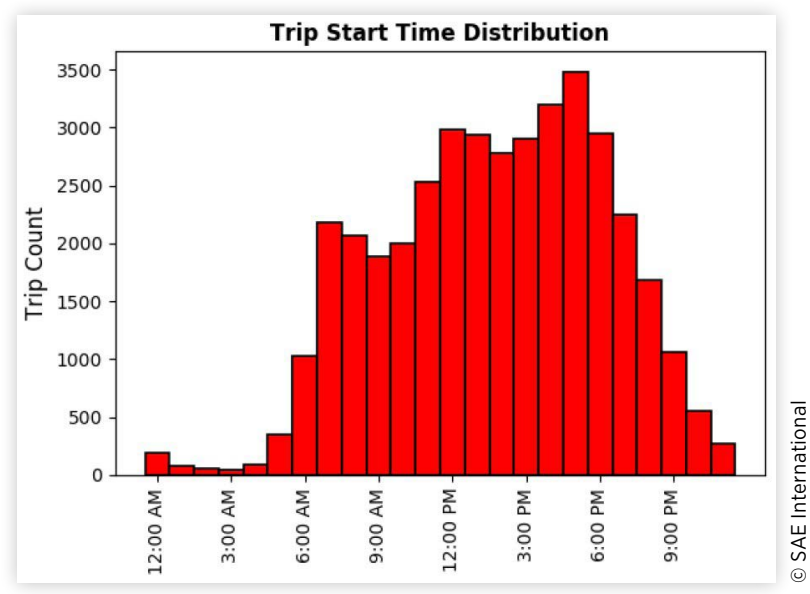

FIGURE 20 TSDC soak time distribution.

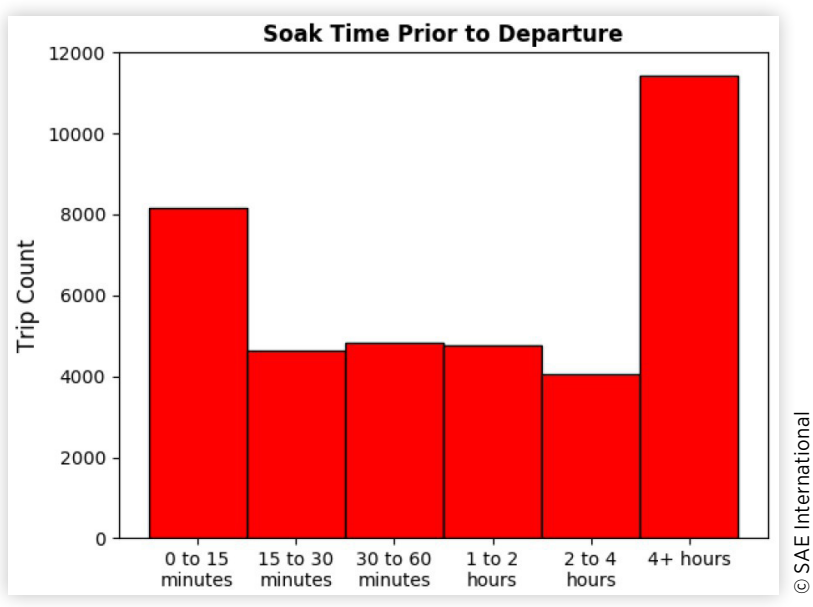

FIGURE 21 Weighted percent vehicle miles traveled (VMT) as a function of ambient temperature.

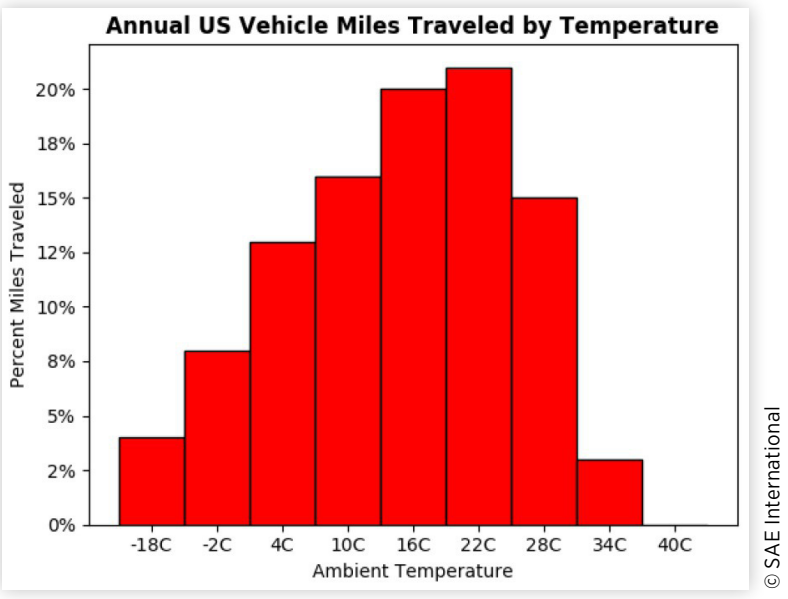

system, simulations above $+20^{\circ} \mathrm{C}$ are omitted under the assumption that consumers will not operate cabin heating above this threshold. Additionally, cabin heating is controlled during real-world simulations with a cabin temperature set point of $+22^{\circ} \mathrm{C}$ to emulate realistic consumer operation of the cabin heating system.

Prior research investigating thermal impacts on vehicle fuel economy involved applying Typical Meteorological Year (TMY) temperature profiles during powertrain simulations $[20,21]$. Incorporating TMY temperatures was not pursued during this investigation because similar real-world weighted temperature effects can be captured by applying several static ambient temperatures and adjusting for the distribution described by Figure 21. Additionally, prescribing only the temperatures of interest $\left(<+20^{\circ} \mathrm{C}\right)$ avoids simulating TMY temperature profiles outside of the scope of the investigation.

\section{Results}

TSDC vehicle information facilitates relating successive trips taken by a single vehicle throughout a study to more thoroughly investigate real-world impacts of the 2-Layer system. 
Temperature profiles for each component were constructed on a much more comprehensive time horizon by combining TSDC vehicle information, derived thermal model dynamics (during vehicle key-on and key-off), and the prescribed ambient temperature throughout a given simulation. Figure 22 shows time series information for a single vehicle over the course of an approximately one-week period from September 2 to September 8 with a magnified portion of three hours on September 5.

Within the figure, TSDC real-world vehicle speed profiles are shown with the modeled temperature profiles of the engine oil, engine coolant, and vehicle cabin in response to the power requirements of the trips. The impact of the driving profiles on the component thermal states can be clearly seen; temperature values decay to ambient while the vehicle is off and rise to operating values as trips begin. Additionally, the relationship between successive trips is illustrated in the magnified time window. The initial values for the second trip are heavily influenced by the final values of the previous trip. The fuel economy benefits of the 2-Layer system is thus achieved by incorporating both real-world trip profiles as well as trip distributions as compared to certification dynamometer testing.

\section{FIGURE 22 Time series examples of thermal simulations} predicting engine oil, engine coolant, and cabin temperatures. The corresponding real-world drive cycle information is overlaid as well. Results are shown at two time windows: one week (top) and 3 hours (bottom).

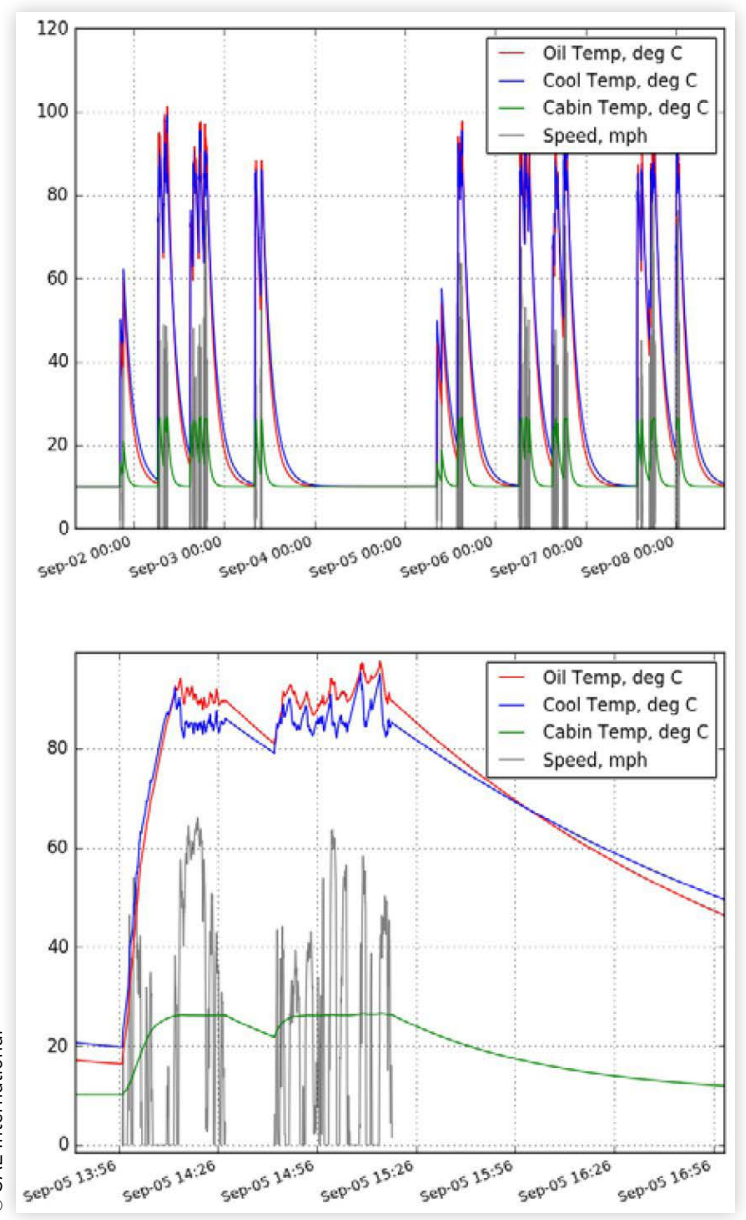

\section{Fleet Level Results}

The methodology for simulating a series of trips driven by a single vehicle described in the previous section was performed for every vehicle within the TSDC. TSDC simulations were performed with the technology active and inactive for prescribed ambient temperatures from $-20^{\circ} \mathrm{C}$ to $+15^{\circ} \mathrm{C}$. Results from the simulations reiterate the importance of including temperature effects within the analysis. For instance, the average fuel economy rose from $19.7 \mathrm{mpg}$ within $-20^{\circ} \mathrm{C}$ ambitions conditions to $21.1 \mathrm{mpg}$ within $+15^{\circ} \mathrm{C}$ ambient conditions with the 2-Layer system active when tested over an appreciable portion of the TSDC cycles. Figure 23 shows a more detailed comparison of fuel economy results by illustrating fuel economy distribution results at the trip level.

Although understanding the impact ambient temperature plays on vehicle energy consumption is important, the primary focus of this investigation was to identify the fuel economy benefits when the 2-Layer system is active versus inactive. As discussed in the Drive Cycle Results Overview section, the 2-Layer system primarily impacts fuel economy by expediting engine oil warmup and reducing the impact of cold starts. Figure 24 shows a scatter plot relating the fuel economy improvement at the trip level to trip information, trip initial oil temperatures and trip average speed (including stops), during a simulation over a portion of TSDC cycles with an applied ambient temperature of $-20^{\circ} \mathrm{C}$. Note that the trips are not simulated in isolation; the starting oil temperature of a given trip is a function of the final temperature from the previous trip and the dwell time between trips. As such, the initial temperature for the same trip varies between simulations for the 2-Layer system activated and deactivated; the initial temperature used in the figure is for the disabled baseline case.

Interestingly, the technology shows the largest benefit for trips with lower average speeds and warmer initial oil temperatures. The former conclusion agrees with the test results which showed a higher technology benefit during the UDDS than the more aggressive US06 (shown for reference). However, the increase in benefit at warmer oil temperatures is somewhat

FIGURE 23 Distribution of trip-level vehicle fuel economies for separate TSDC simulations with two ambient temperatures applied. The 2-Layer system is active in each case.

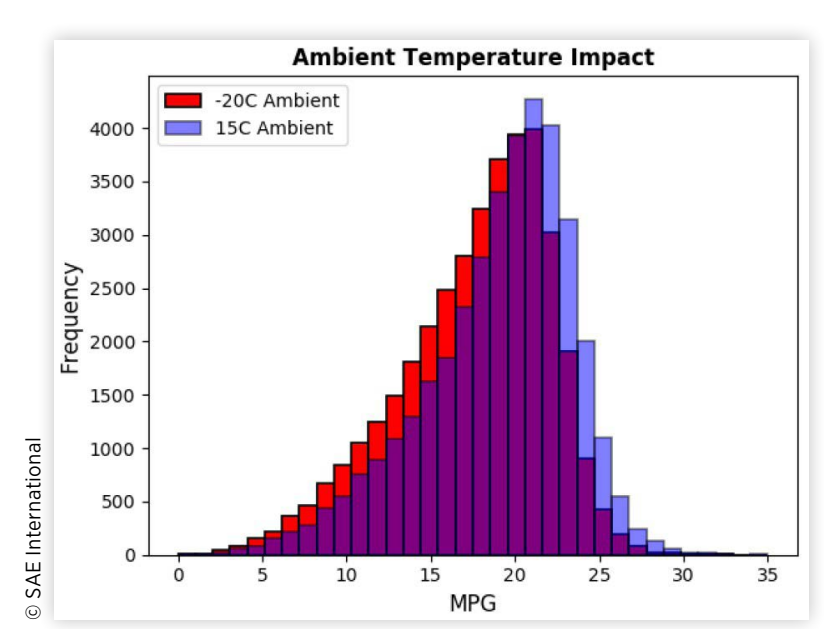


FIGURE 24 Scatter relating fuel economy improvement attributed to the 2-Layer technology at the trip level in association with the trip initial oil temperature for the baseline simulation and the trip average speed. The scatter points shown represent a portion of the trips simulated within this study.

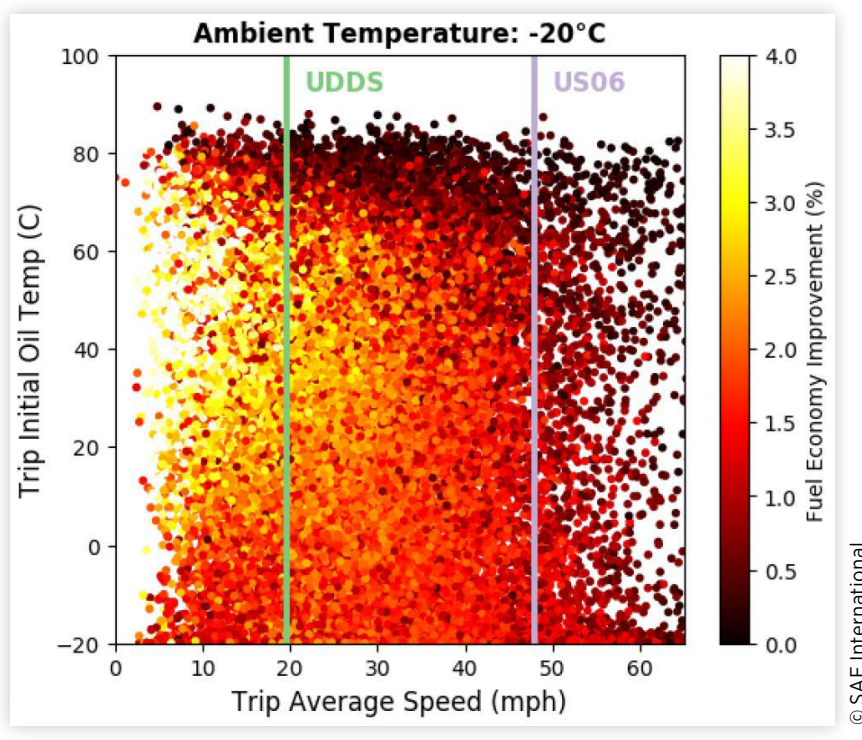

counter intuitive as the 2-Layer system is active the longest during cold starts. One explanation for a larger benefit during warmer starts is that after long dwell times, the initial oil temperatures for a given trip are similar for the 2-Layer in both activated and deactivated cases. However, a trip starting after a shorter dwell time will benefit from the differential oil temperature from the final conditions of the previous test. Note that this benefit at warmer temperatures is diminished for higher average speed trips during which the oil temperatures converge sooner and for hot oil temperatures where the system is often deactivated due to HVAC logic.

The aggregate benefit of the technology can be better understood by analyzing the fuel economy results over all simulations performed. Modeling was performed at a range of temperatures to better understand the benefit of the 2-Layer system in a real-world context. Figure 25 contains results for the average fuel economy benefit for different applied ambient temperatures. Improvements range from $1.36 \%$ at $-20^{\circ} \mathrm{C}$ to $0.24 \%$ at $+15^{\circ} \mathrm{C}$. In general, colder temperatures present greater opportunity for the 2-Layer system to improve vehicle fuel economy. The 2-Layer setting is only permitted while the air conditioning compressor is off, which is not permitted above $0^{\circ} \mathrm{C}$ for the $\mathrm{RX} 350$. The bars shaded in light red represent the additional energy savings possible if the compressor operation were disabled in conditions above $0^{\circ} \mathrm{C}$. Note that the cutoff at $0^{\circ} \mathrm{C}$ in Figure 25 varies across vehicles and the results shown only correspond to the 2 -Layer system as it functions in the vehicle tested. Separate model vehicles with the 2-Layer technology may experience larger benefits depending on the respective compressor cutoff temperature.

Identifying a representative fuel economy improvement for the 2-Layer technology requires weighting the fuel economy benefits against the distribution of annual VMT by
FIGURE 25 Fuel economy impact of the 2-Layer system for a range of applied ambient temperatures. Each bar represents a comparison of fuel economy results for full TSDC simulations with the system active and inactive.

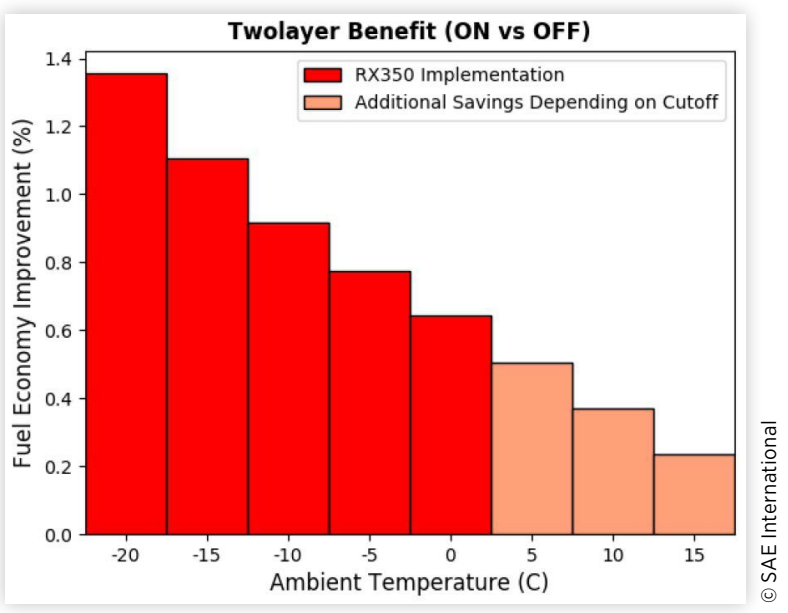

ambient temperature (Figure 21). Doing so results in a weighted fuel consumption benefit of $0.16 \%$ if the technology operates up to $0^{\circ} \mathrm{C}$. If the technology operates in higher ambient temperatures, the weighted fuel consumption benefit increases as shown in Figure 25. For instance, if the technology operates up to $+10^{\circ} \mathrm{C}$, the weighted fuel consumption benefit rises to $0.26 \%$.

\section{Conclusions}

Chassis dynamometer testing and thermally sensitive simplified modeling analysis was performed to better understand the impacts of a 2-Layer HVAC technology on vehicle fuel consumption. In this work, a 2016 Lexus RX350 was tested over various drive cycles and temperatures with the 2-Layer system enabled and disabled to experimentally quantify the fuel consumption benefits of the technology. 5-cycle analysis of the 2-Layer system revealed no opportunity for fuel savings for the highway procedure and a city fuel economy improvement of $0.34 \%$. These two factors resulted in an on-cycle benefit of $0.18 \%$ for 5 -cycle testing and no on-cycle benefit for 2-cycle testing.

A thermally sensitive powertrain model was also created and calibrated against the dynamometer data. The model was able to closely replicate both component thermal profiles as well as vehicle fuel consumption. This model was simulated with the technology enabled and disabled over hundreds of thousands of real world drive cycles and ambient temperature combinations. The simulation results revealed under which conditions the technology proves most beneficial as well as additional potential energy savings if the technology were adjusted. As the system is currently implemented, a real-world benefit of $0.16 \%$ was calculated. Logic control adjustments allowing the 2 -Layer system to operate up to $+10^{\circ} \mathrm{C}$ ambient temperatures were modeled and resulted in an increased weighted fuel consumption benefit of $0.26 \%$. 


\section{References}

1. U.S. Federal Register, Environmental Protection Agency, Department of Transportation, National Highway Traffic Safety Administration, "2016 and Later Model Year LightDuty Vehicle Greenhouse Gas Emissions and Corporate Average Fuel Economy Standards; Final Rule," http://www. gpo.gov/fdsys/pkg/FR-2012-10-15/pdf/2012-21972.pdf, accessed October 1, 2014.

2. U.S. Department of Energy and U.S. Environmental Protection Agency, "Fuel Economy Tests: Detailed Test Information," http://www.fueleconomy.gov/feg/fe test schedules.shtml, accessed November 19, 2014.

3. Ostrouchov, N., "Effect of Cold Weather on Motor Vehicle Emissions and Fuel Economy," SAE Technical Paper 780084, 1978, doi:10.4271/780084.

4. Kunze, K., Wolff, S., Lade, I., and Tonhauser, J., “A Systematic Analysis of CO2 Reduction by an Optimized Heat Supply During Vehicle Warm-Up," SAE Technical Paper 2006-01-1450, 2006, doi:10.4271/2006-01-1450.

5. Jehlik, F., Rask, R., and Christensen, M., "Development of Variable Temperature Brake Specific Fuel Consumption Engine Maps," SAE Technical Paper 2010-01-2181, 2010, doi:10.4271/2010-01-2181.

6. Andrews, G.E., Harris, J.R., and Ounzain, A., "SI Engine Warm-Up: Water and Lubricating Oil Temperature Influences,"

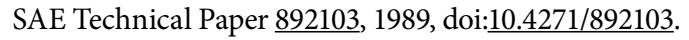

7. Andrews, G.E., Harris, J.R., and Ounzain, A., "Experimental Methods for Investigating the Transient Heating and Emissions of an SI Engine During the Warm-Up Period," in: Experimental Methods in Engine Research and Development, IMechE, pp.101-108, 1988.

8. Andrews, G.E., Ounzain, A.M., Li, H., Bell, M. et al., “The Use of a Water/Lube Oil Heat Exchanger and Enhanced Cooling Water Heating to Increase Water and Lube Oil Heating Rates in Passenger Cars for Reduced Fuel Consumption and CO2 Emissions During Cold Start," SAE Technical Paper 2007-012067, 2007, doi:10.4271/2007-01-2067.

9. Neubauer, J. and Wood, E., "Accounting for the Variation of Driver Aggression in the Simulation of Conventional and Advanced Vehicles," SAE Technical Paper 2013-01-1453, doi:10.4271/2013-01-1453.

10. Wood, E., Gonder, J., and Jehlik, F., “On-Road Validation of a Simplified Model for Estimating Real-World Fuel Economy," SAE Journal 2017-01-0892, 2017, doi:10.4271/2017-01-0892.

11. Imahigashi, S., Sakai, M., Yoshino, E., and Mitsuishi, Y., "Compact High-Efficiency 2-Layer Blower Fan for HVAC," SAE Journal 2016-01-0193, 2017, doi:10.4271/2016-01-0193.

12. Argonne National Laboratory, Transportation Technology R\&D Center "Advanced Powertrain Research Facility (APRF)," http://www.transportation.anl.gov/facilities/aprf. html, accessed October 1, 2014.

13. Myers, R.H. and Montgomery, D.C., "Response Surface Methodology: Process and Product Optimization Using Designed Experiment," (Wiley-Interscience, 1995).

14. National Renewable Energy Laboratory, "National Solar Radiation Database, Typical Meteorological Year Database
3," Golden, CO, http://rredc.nrel.gov/solar/old data/ nsrdb/1991-2005/tmy3/, accessed July 2016.

15. Data generated using Engineering Equation Solver (EES), V9.649-3D which contains built in thermodynamic and physical properties of unused engine oil, http://www.fchart. com/ees/.

16. “J-2951 Dynamometer Repeatability Testing," ANL internal study, 2013. http://standards.sae.org/j2951_201611/.

17. National Renewable Energy Laboratory, "Future Automotive Systems Technology Simulator," www.nrel.gov/fastsim, accessed October 1, 2013.

18. “Transportation Secure Data Center," (2013). National Renewable Energy Laboratory, www.nrel.gov/tsdc, accessed October 1, 2013.

19. Environmental Protection Agency, "Final Rulemaking for 2017-2025 Light-Duty Vehicle Greenhouse Gas Emission Standards and Corporate Average Fuel Economy Standards," 2012.

20. Jehlik, F., Wood, E., Gonder, J., and Lopp, S., "Simulated RealWorld Energy Impacts of a Thermally Sensitive Powertrain Considering Viscous Losses and Enrichment," SAE Int. J. Mater. Manf. 2017-01-0158, https://www.nrel.gov/ docs/fy15osti/63255.pdf.

21. National Renewable Energy Laboratory, "National Solar Radiation Database, Typical Meteorological Year Database 3," Golden, CO, http://rredc.nrel.gov/solar/old data/ nsrdb/1991- 2005/tmy3/, accessed July 2011.

\section{Contact Information}

Advanced Powertrain Research Facility Argonne National Laboratory Energy Systems Division 9700 S. Cass Ave.

Argonne, IL 60439

\section{Forrest Jehlik}

(630) 252-6403

fjehlik@anl.gov

Transportation and Hydrogen Systems Center National Renewable Energy Laboratory

15013 Denver West Pkwy MS 1634

Golden, CO 80401

Eric Wood

(303) 275-3290

eric.wood@nrel.gov

Matthew Moniot

(303) 275-4839

matthew.moniot@nrel.gov

Toyota Motor North America

Research \& Development | Performance Development 2

1555 Woodridge Ave

Ann Arbor, MI 48105

Hidekazu Hirabayashi

(734)995-4085

hidekazu.hirabayashi@toyota.com 
Netsanet Chevers

(734) $995-2662$

netsanet.chevers@toyota.com

DENSO International America

Thermal Systems R\&D Climate Control

24777 DENSO Dr.

Southfield, MI 48033

Masahiro Nomura

(248)372-8537

Masahiro nomura@denso-diam.com

Yuanpei Song

(248)750-3749

Yuanpei song@denso-diam.com

\section{Acknowledgments}

The authors would specifically like to thank Vehicle Systems Program Managers David Anderson for their guidance.

Use of Argonne National Laboratory's Advanced Powertrain Research Facility and the National Renewable Energy Laboratory's FASTSim software (both developed under funding from the U.S. Department of Energy's Vehicle Technologies Office) were critical to the completion of this study.

The U.S. Government retains and the publisher, by accepting the article for publication, acknowledges that the U.S. Government retains a nonexclusive, paid-up, irrevocable, worldwide license to publish or reproduce the published form of this work, or allow others to do so, for U.S. Government purposes.

\section{Definitions/Abbreviations}

5-cycle - U.S. Environmental Protection Agency fuel economy certification cycles: city, highway, high speed, air-conditioning, and cold temperature tests

${ }^{\circ} \mathrm{C}$ - degrees Celsius

ANL - Argonne National Laboratory

APRF - Advanced Powertrain Research Facility

EPA - U.S. Environmental Protection Agency

FASTSim - Future Automotive Systems Technology Simulator g - Gram

HWFET - Highway dynamometer driving schedule (EPA defined)

km - Kilometer

mpg - Miles per gallon

NREL - National Renewable Energy Laboratory

TMY - Typical meteorological year

UDDS - Urban Dynamometer Driving Schedule (EPA defined)

UDDSx 2 - back-to-back UDDS driving tests

US06 - US06 dynamometer driving schedule (EPA defined)

US06x2 - back-to-back US06 dynamometer driving tests

VMT - Vehicle miles travelled

This is the work of a Government and is not subject to copyright protection. Foreign copyrights may apply. The Government under which this paper was written assumes no liability or responsibility for the contents of this paper or the use of this paper, nor is it endorsing any manufacturers, products, or services cited herein and any trade name that may appear in the paper has been included only because it is essential to the contents of the paper. 